\title{
Designing Mobile Application for the Over the Counter Drug Marketing
}

\author{
Vasja Roblek, Maja Meško \\ University of Primorska, Faculty of Management, Koper, Slovenia
}

\begin{abstract}
The increased usage of mobile apps has a great potential in Pharmacy market. Through the use of mobile apps, web portals and social media may allow a fast and wide diffusion of awareness for over the counter (OTC) drugs and attract a large number of customers, thus increasing the value of searching for information, quality and lower costs of the purchase. The goal of this paper is to identify the key factors as antecedents of customer satisfaction for the design of a mobile app for OTC drug marketing. To this aim, the authors use the Kano model that allows categorizing service attributes according to how they are perceived by customers and estimating their impact on customer satisfaction. This model is adopted in order to identify, express and latent needs of customers and to design a mobile app for OTC marketing according to their perceptions and expectations. To apply the Kano model, the authors used quantitative data collected through 537 questionnaires that were sent to the Slovenian internet users (June and August 2013). The results of this analysis can be relevant to the pharmaceutical companies; drugs vendors and marketing managers plan strategy and operational activities, for pharmaceutical companies in the field of OTC drugs marketing, for application developers, and for all those concerned with OTC drugs marketing issues.
\end{abstract}

Keywords: OTC drugs, mobile applications, Kano model, customer satisfaction, mobile marketing

JEL classification: M10, M31, F14, K23, L65, L81

\section{Introduction}

The paper is focused on the research of customer satisfaction with Web 2.0 applications for over the counter (OTC) drugs marketing. The pharmaceutical industry and drugs retailers become award about the importance of Web 2.0 as a channel of communication with consumers. OTC market has become a mature market, because more and more people are aware of the importance of maintaining a healthy fitness and active lifestyle (Roblek and Bertoncelj, 2014). We argue that the pharmaceutical industry pharmacists and physicians are increasingly using the internet and social media as one of the forms in the process of organizational change and adaptation responses to widespread use of internet and social media by consumers (e.g. patients) (Roblek, 2015). By that, the pharmaceutical industry provides competitive advantage, creates goodwill, public awareness about their products and services and gives access to knowledge (Bughin, Chui and Manyika, 2010). Consequently, the use of Web 2.0 offers the competitive advantage and increases added value, both for providers and for consumers(lower cost of access to information, services and products, higher margins) (Roblek, 2015).

A very important factor in the context of digital marketing that effect on consumer satisfaction is the question of the quality of providing products and 
services online (Roblek, 2015; Roblek and Bertoncelj, 2014). Online retailers of the OTC drugs must not overlap the real facts about the products or offered counterfeit products, which could later affect the health and satisfaction of the customers.

The goal of the paper is to identify the expectations of the OTC drug marketing mobile applications users and obtain relevant characteristics that can help to mobile application developers.

We have developed two research questions for the purpose of this research according to the baseline of a Kano model (Saverwein et al., 1996), i.e.:

$R Q$ 1: Which features of the Web 2.0 application can be used to obtain a high level of a customer satisfaction?

RQ2: Which of the web 2.0 applications features have a more than proportional influence on satisfaction and which attributes are an absolute must in the eyes of customer?

The first part of the paper is focused on the introduction of the problem. The main part of the paper presents research. This chapter is more accurately defining the Kano model. The penultimate chapter is focused on the analysis of the results of research with using the Kano model. The paper is concluded with a discussion and conclusions.

\section{Methodology}

Sample

In order to test the research propositions, a questionnaire survey method was used to collect the responses from Slovenian users of the internet. During the June and August 2013, questionnaires were distributed to email addresses. It was addressed to the individuals who were asked to fill in the questionnaire themselves. To maintain external validity, we tried to sample data from different respondent groups (faculties, companies, mails from friends).

A total of 3000 invitations to the research were distributed, of which a total of 630 were returned (a response rate of $21 \%$ ). After eliminating 93 responses due to incompleteness or the absence of Internet shopping experience, a sample of 537 $(17.9 \%)$ was ultimately employed in our empirical analysis. According to Dilman (1999), our response rate is comparable with similar research using mail surveys. The sample includes 231 women and 306 men. Sample data on individuals revealed that from the 537 respondents, more than half belong to the age group between 30 to 40 years, 58 percent. The second most represented age group is over 40 , with $30 \%$, with 11 percentages followed group 20-29 and the smallest group is 15 to 19 years only $2 \%$. Primary education and less have $6 \%$, vocational education have $15 \%$, secondary education have $49 \%, 1$ \&2 Bologna cycle have $27 \%$ and 3 Bologna cycle have $3 \%$ of the respondents. Without income is $2 \%$, less than 546 EUR of the income is $16 \%$, between 565 and 1001 EUR of income is $61 \%$, between 1002 and 1991 EUR of income is $17 \%$ and more than 1992 EUR have $17 \%$ of respondents. $1 \%$ of the respondents live in the village that has under 999 citizens, in tows between 1.000 and 4.999 citizens live $6 \%$, in towns between 5.000 and 9.999 citizens live 59\%, in towns with over 10.000 and to 49.999 citizens live $33 \%$ and in towns over the 50.000 citizens live $1 \%$ of the respondents.

\section{Applying the Kano model}

In the paper Roblek and Bertoncelj (2014) we used thestructural equation modelling for the testing of three models. We confirmed in model 1 that consumer satisfaction with safety and information has a significant effect on theconsumer trust. 
In the model 2 it was confirmed that that the consumer trust also has a significant effect on virtual brand loyalty. The results of model 3 show a partial mediator effect of consumer trust regarding the relationship between consumer perception of corporate social responsibility and virtual brand loyalty. In this paper we decided to test the data collected through the questionnaire was analysed with using the model proposed by Noriaki Kano (1984) to find the ideal characteristics of an epharmacy OTC market that can better satisfy customer expectations.

We used the Kano model because of its advantages prior structural equation modelling (Dominici and Palumbo, 2013):

1. The Kano Model can be applied before designing the customer's ideal product or service and after, when it is used for estimates the consumption experience.

2. Compared with other models, the Kano Model does not assume the existence of a linear relationshipbetween product/service performance and customer satisfaction. Kano noticed that customers' requirements are not equivalent and that some requirements, in fact, are capable of generating more satisfaction than others. Customer satisfaction is not always proportional to the functionality of the good, which implies that higher quality does not necessarily lead to higher satisfaction for all productattributes or services requirements.

Kano classified product/service attributes into sixcategories based on their impact on customer satisfaction (Kano et al., 1984):

$>$ Must-be (M) (dissatisfier or basic factors): customers consider these requirements as basic factors; thus, their presence will not increase customers' satisfaction level significantly while their absence will cause extreme dissatisfaction.

$>$ One-dimensional (O) (performance factors): these factors cause satisfaction if their performanceis high while they cause dissatisfaction if their performance is low. These attributes are linear and symmetric because they are typically connected to customers' explicit needs and desires. The company should try to be competitive here.

$>$ Attractive (A) (satisfiers or excitement factors): these requirements cause customer satisfactionif delivered while they do not cause dissatisfactionif they are not. The company can use thesefactors to distinguishitself from its competitors ina positive way.

$>$ Indifferent (I): customers do not care about thesefeatures either way.

$>$ Reverse (R): customers do not desire these product attributes and also expect the reverse.

$>$ Questionable (Q): It is unclear whether customersexpect these attributes because they gave unusableresponses due to misunderstanding the questions on the research or making an error when filling out the questionnaire.

The horizontal axis in the Kano diagram is the state of fulfilment of a certain quality attribute while the vertical axis displays customer satisfaction with a certain quality attribute (Kano et al., 1984). In Kanodiagram, only the first four requirements are represented. 


\section{Results}

\section{Implementation of the Kano model}

The authors of the Kano model provided their own approach to identifying customer needs and for developing Kano questionnaire. Kano's questionnaire is characterized by pairs of customer requirement questions. Each question is composed of two parts:

1. How do you feel if feature $X$ is present in the product/service? (functional form of question).

2. How do you feel if feature $X$ is not present in the product/service? (dysfunctional form of the question).

The data are then analysed by means of a special evaluation table, which results in a categorisation of attributes for each respondent. For each functional and dysfunctional question, the customer can select one of five alternative answers, which are expressions of different degrees of customer perceptions: (1) I like it that way, (2) It must be that way, (3) I'm neutral, (4) I can live with it that way, and (5) I dislike it that way. Crossing the answers for the functional and dysfunctional questions for every questionnaire, through the help of a matrix formulated by Kano, customer perceptions can be evaluated into quality dimensions. Frequencies of singlerespondent categorisations are then used to provide the final classification of attributes in our case are presented in table 1 (Mikulic and Prebezac, 2011).

From the results in Table 1 is evident that it comes to the major differences between the requirements of the maximum frequency and the frequencies of the other characteristics. The questionable results $(Q)$ and the reverse results (R) have extremely low frequencies, implying that the questionnaire had a high reliability.

A user friendly platform requirement cannot be classified in only one category, because it is too low difference between the highest frequency and other frequencies of the characteristics. We used the $M>O>A>1$ rule to organize the importance of the requirements.

The users considered the control on online OTC drugs shop as more important as competent sellers and user friendly platform (whose frequency is between must be and questionable). The flexibility on buying OTC drugs is more attractive then better access to the information. Customers are indifferent to the on line pharmacists consulting.

Table 1

Classification of the requirements according to the Kano model

\begin{tabular}{|c|c|c|c|c|c|c|c|}
\hline & 0 & $M$ & A & 1 & $\mathbf{R}$ & $\mathbf{Q}$ & $\begin{array}{l}\text { Requirement } \\
\text { category }\end{array}$ \\
\hline User friendly platform & 191 & 219 & 102 & 21 & 4 & 0 & Must be \\
\hline $\begin{array}{l}\text { On line pharmacists } \\
\text { consulting }\end{array}$ & 91 & 87 & 107 & 231 & 17 & 4 & Indifferent \\
\hline Competent sellers & 17 & 357 & 139 & 24 & 0 & 0 & Must be \\
\hline $\begin{array}{l}\text { Flexibility on buying OTC } \\
\text { drugs } 24 \mathrm{~h}\end{array}$ & 31 & 161 & 206 & 125 & 8 & 6 & Attractive \\
\hline $\begin{array}{l}\text { Better access to the } \\
\text { information }\end{array}$ & 21 & 147 & 183 & 141 & 29 & 16 & Attractive \\
\hline $\begin{array}{l}\text { Control on online OTC drugs } \\
\text { shop }\end{array}$ & 4 & 487 & 46 & 0 & 0 & 0 & Must be \\
\hline
\end{tabular}

Source: Authors 


\section{Interpretation and evaluation of the Kano model}

We are going to analyse the data from table 1 with using customer satisfaction index. This method was developed by Berger et al. in 1993. The customer satisfaction coefficient indicates if satisfaction can be improved by meeting a product requirement or if fulfilling this product requirement just prevents the customer from being dissatisfied (Berger et al., 1993). The results are shown in table 2.

1. Customer satisfaction index (CS):

$(C S)=\frac{A+O}{M+O+A+I}$

The customer satisfaction index has a value between 0 and 1 (values close to 1 indicate great satisfaction while values close to 0 indicated low satisfaction).

2. Customer dissatisfaction index (CD):

$(C D)=\frac{M+O}{M+O+A+I} *(-1)$

The customer dissatisfaction index can have a value between -1 and 0 (values close to -1 indicate great dissatisfaction while values close to 0 indicate low dissatisfaction).

Table 2

Customer satisfaction and customer dissatisfaction indexes for each app requirement

\begin{tabular}{lrc}
\hline App requirement & CS & CD \\
& & \\
User friendly platform & 0,55 & $-0,77$ \\
On line pharmacists consulting & 0,38 & $-0,34$ \\
Competent sellers & 0,29 & $-0,70$ \\
Flexibility on buying OTC drugs 24 $\mathbf{h}$ & 0,45 & $-0,37$ \\
Better access to the information & 0,41 & $-0,52$ \\
Control on online OTC drugs shop & 0,09 & $-0,91$ \\
\hline
\end{tabular}

Source: Authors

The interpretation of the CS:

> The user friendly platform has the greatest impact on customer satisfaction. If we consider Kano model then the user friendly platform is situated between $M$ -that has no influence on satisfaction and $O$ that has influenced on higher satisfaction because his performance is high.

$>$ Control on online OTC drugs shop, competent sellers and on line pharmacists consulting have love levels on the customer satisfaction index. These results are must be (control on online OTC drugs shop and competent sellers) and indifferent (on line pharmacists consulting). Their presence has according to the Kano model no influence to the customer satisfaction.

The explanation of the CD:

$>$ The non-inclusion of control on online OTC drugs shop, user friendly platform and competent sellers are caused the greatest level of dissatisfaction. According to the Kano model both requirements are must be and their absence is causing extreme dissatisfaction. 
> The on line pharmacists consulting and flexibility on buying OTC drugs $24 \mathrm{~h}$ have the lowest degree of dissatisfaction. The flexibility on buying OTC drugs $24 \mathrm{~h}$ is an A requirement. They do not cause an expressed dissatisfaction. By the on line pharmacist consulting customers do not care about these features either way.

The results of customer satisfaction and customer dissatisfaction indexes confirm the Kano models results.

\section{Discussion and conclusion}

Based on Kano model it is evident that no one of requirements are not having a high influence on the customer satisfaction. The user friendly platform has a more than proportional influence on satisfaction.

The customers exposed as a must be requirements in Web 2.0 applications the control on online OTC drugs shop, competent sellers and user friendly platform. Customers are recognising the need for security in e-commerce. In the business environment it is necessary to be aware of the negative consequences of IT developments such as the emergence of high-tech crime. The abuse of information communication technologies is increasing. Crimes are divided into one where computers are used as a means to commit or as the object of enforcement of criminal activity in the area of illegal use of the internet. Due to increasing sales of counterfeit medicines and posts false information on medicines with the intention of misleading the customer it has to be provided a stricter control on the internet and social media content.

The limitation of the research is that it is geographically limited to Slovenia and it is specialised on the OTC market mobile applications. According to sociodemographical factors of the respondents the results of the research can only determine specific customer behaviour and preferences for Slovenian market.

Further research might include only an analysis of the quality and user satisfaction with a particular function of mobile apps. The advantage of the research is that it can be implemented in other cultural areas.

\section{References}

1. Berger, C., Blauth, R., Boger, D., Bolster, C., Burchill, G., DuMouchel, W., et al. (1993), "Kano's method for understanding customer-defined quality", Center for Quality of Management Journal, Vol 2 No 4, pp. 3-35.

2. Bughin, J., Chui, M., Manyika, J. (2010), "Clouds, big data, and smart assets: Tentechenabled business trends to watch", McKinsey Quarterly, Vol 56 No 1, pp. 75-86.

3. Dilman, I. (1999) "Free Will: An Historical and Philosophical Introduction", Psychology Press

4. Dominici, G. and Palumbo, F. (2013), "How to build an e-learning product: Factors forstudent/customer satisfaction", Business Horizons, Vol. 56 No. 1, pp. 87-96.

5. Ennew, T.C., Binks, R.M. and Chiplin, B. (2015), "Customer satisfaction and customer retention: an examination of small business and their banks in the UK", in Wilson, J.E. and Black,C.W. (Ed.), Proceedings of the 1994 Academy of Marketing Science (AMS) Annual Conference, Springer International Publishing, Berlin, pp. 182-199.

6. Fornell, C. Johnson, D.M., Anderson, E.W., Cha, J. and Bryant, E.B. (1996), "The American Customer Satisfaction Index: Nature, Purpose, and Findings", Journal of Marketing, Vol. 60, pp. 7-18.

7. Homburg, C., Wieseke, J. and Hoyer, D.W. (2009), "Social Identity and the Service-Profit Chain," Journal of Marketing, Vol. 73, pp. 38-54.

8. Kano N., Seraku NK., Takahashi F., Tsuji S. (1984), "Attractive quality and must be quality", The Journal of the Japanese Society for Control Quality, Vol.14, pp.39-48. 
9. Mikulic, J., Prebezac, D. (2011),"A critical review of techniques for classifying quality attributes in the Kano model", Managing Service Quality: An International Journal, Vol 2 Nol, pp 46-66.

10. Roblek, V., Bertoncelj, A. (2014), "Impact of corporate social responsibility on OTC medicines consumers", The Amfiteatru Economic, Vol. 35 No 16, pp. 12-35.

11. Roblek, V. (2015), "Impact of Internet and social media on organizational change of OTC medicines marketing management", International Journal of Electronic Marketing and Retailing, Vol. 7 No 1, forthcoming.

12. Saverwein, E., Bailom, F., Matzler, K., Hinterhuber, H.H. (1996), "The Kano model: how to delight your customers", Preprints Volume I of the IX. International Working Seminar on Production Economics, Innsbruck/Igls/Austria, February, pp. 19-23.

\section{About the authors}

Vasja Roblek, MSc, is a PhD student at the Faculty of Management, University of Primorska, Koper, Slovenia. His research's area includes management, innovative economy, sustainable development, marketing, internet and qualitative methodology. He has published several scientific papers in international journals and he is a co-author of thetwo book chapters in Springer monographs. Author can be contacted at vasja.roblek@gmail.com

Maja Meško, PhD held a position of associate professor of management at University of Primorska, Faculty of management. Previous she worked for Ministry of Transport, Civil Aviation Directorate (CAA - civil aviation authorities) and for Slovenian Air Navigation Services - Slovenia control, Ltd. Since 2013 she has been registered by European association for aviation psychology as a certificated human resource specialist. Her work, which includes around 200 bibliographical items, has been published in professional and academic journals. She is also ultra-light licence holder. She is a member of the supervisory board of Civil Aviation Agency in Slovenia. Author can be contacted at maja.mesko@fm-kp.si 